УДК 796 (07): 378

https://doi.org/10.36906/FKS-2021/35

Работа выполнена при финансовой поддержке ФГБОУ ВО «Мордовский государственный педагогический университет им. М.Е. Евсевьева

в рамках научного проекта «Проектирование трансдисциплинарных образовательных ресурсов в условиях практико-ориентированной подготовки будущего педагога физической культуры договор №MK-032-21 от 26.04.2021».

Жабаков В.E.

ORCID: 0000-0003-0897-1840, канд. пед. наук; Макаренко В.Г. ORCID: 0000-0001-5651-4543, д-р пед. наук

Южно-Уральский государственный гуманитарно-педагогический университет

2. Челябинск, Россия

\title{
ТЕОРЕТИКО-МЕТОДИЧЕСКИЕ АСПЕКТЫ ПРАКТИКО-ОРИЕНТИРОВАННОЙ ПОДГОТОВКИ БУДУЩИХ ПЕДАГОГОВ ФИЗИЧЕСКОЙ КУЛЬТУРЫ
}

Аннотация. Теоретические аспекты практико-ориентированной подготовки будущих педагогов физической культуры включает модель активного трансдисциплинарного обучения, технологии обучения студентов, воспроизведение реальных профессиональных ситуаций возможно в условиях имитационного моделирования. Результат практико-ориентированной подготовки представлен в виде политомических «переходов», обеспечивающих качественные изменения результатов.

Ключевые слова: трансдисциплинарность, политомические «переходы», подготовка будущих педагогов физической культуры.

Zhabakov V.E. ORCID: 0000-0003-0897-1840, Ph.D.; Makarenko V.G. ORCID: 0000-0001-5651-4543, Ph.D. South Ural State Humanitarian Pedagogical University Chelyabinsk, Russia

\section{THEORETICAL AND METHODOLOGICAL ASPECTS OF PRACTICAL-ORIENTED TRAINING OF FUTURE TEACHERS OF PHYSICAL EDUCATION}

Annotation. Theoretical aspects of practice-oriented training of future physical education teachers include a model of active transdisciplinary training, technologies for teaching students; reproduction of real professional situations is possible in the conditions of simulation modeling. The result of practice-oriented training is presented in the form of polytomic "transitions" that ensure qualitative changes in the results.

Keywords: transdisciplinarity, polytomic "transitions", training of future physical education teachers. 
На современном этапе трансформации не только содержания, но и аксиологической направленности высшего образования особенно важно ввести актуальные для будущих педагогов целевые ориентиры подготовки в вузе, поскольку именно учитель физической культуры в большей степени нуждается в формировании системы практически востребованных знаний и умений, «владениях» современными методами обучения. Поэтому разработка теоретико-методических основ практико-ориентированной подготовки в соответствии с современными требованиями ФГОС 3++ является актуальной.

Анализ проблемы практико-ориентированной подготовки позволяет выделить основные теоретические тенденции рассмотрения данного феномена. Во-первых, на первый план выходит модель активного трансдисциплинарного обучения студентов в небольших по составу группах, а не традиционные формы организации учебного процесса. Например, работа над проблемно-ориентированными кейсами предполагает организацию обсуждения проблемы в микрогруппах. Следовательно, практико-ориентированная подготовка будущих педагогов физической культуры включает проектирование моделей взаимодействия студентов в условиях трансдисциплинарной образовательной среды, «имеющей дело со сложными, саморазвивающимися системами» [3, с. 63]. Именно трансдисциплинарность задает контекст универсализации подготовки будущих педагогов физической культуры, в этом конкретном случае через конгруэнтность развития телесности личности и формирования когнитивного потенциала личности. Так, результатом активного трансдисциплинарного обучения следует считать концептуальное мышление, которое представляет собой не только отражение концептов практико-ориентированной подготовки в новых, непривычных сочетаниях и связях, но и рационально-логическое решение кейсовых задач.

Во-вторых, практико-ориентированная подготовка будущих педагогов физической культуры включает такие технологии обучения студентов, которые направлены на увеличение практической составляющей подготовки и позволяют сочетать, по мнению Л.В. Павловой [5] теоретическую подготовку в вузе и практическую работу. Такое воспроизведение реальных профессиональных ситуаций возможно в условиях имитационного моделирования. Моделирование процессов деятельности будущих педагогов по формированию умений и способов действий в реальной педагогической ситуации относится к признакам имитационного моделирования. Для реализации имитационного моделирования мы использовали систему деловых игр, направленных на освоение дисциплины «Педагогическое физкультурно-спортивное совершенствование», которые позволяют нам сформировать у студентов механизмы выбора способов решение педагогических ситуационных задач.

В-третьих, теоретический конструкт «результат практико-ориентированной подготовки» отражает последовательность действий, направленных на организацию подготовки студентов, качественно-количественные «атрибуты» процесса обучения, которые определяются направленностью основной профессиональной образовательной программы. Однако для нас представляет интерес изменения, трансформации, что также можно считать результатом практико-ориентированной подготовки. Представим результат практикоориентированной подготовки в виде политомических «переходов». Так, в процессе практикоориентированной подготовки роль педагога возможно охарактеризовать через переход от «носителя единственно верного знания» к модератору и фасилитатору процесса обучения. Трансформация роли знания как основы практико-ориентированной подготовки осуществляется в процессе перехода от академического, абстрактного знания «для всех» к осмысленному значимому знанию «для себя». Изменение форм обучения также можно представить через «переходы»: от традиционных, классических, семинарских к активным, моделирующим контекст будущей профессиональной деятельности. Формирование 
содержания учебных дисциплин в условиях практико-ориентированной подготовки также включает логику «переходов»: от базовой информации к практическим сведениям, от целей и задач каждой учебной дисциплины к «субъектно-ориентированному» контексту обучения.

Таким образом, актуализация теоретических аспектов практико-ориентированной подготовки, направленная на трансдисциплинарную модификацию процесса обучения и трансформацию представлений о результате практико-ориентированной подготовки, обусловили необходимость проектирования индивидуальных образовательных маршрутов будущих педагогов физической культуры.

В.Е. Жабаков предлагает внедрение в практико-ориентированную подготовку будущих педагогов физической культуры трансдисциплинарных образовательных маршрутов [2, с. 178]. Целью реализации трансдисциплинарных индивидуальных образовательных маршрутов является не только достижение будущим педагогом физической культуры определенного уровня образованности (грамотности, функциональной грамотности, компетентности), но и проектирование трансдисциплинарных вариантов прохождения по индивидуальному маршруту.

Первый блок технологии проектирования индивидуальных образовательных маршрутов, в соответствии с концепцией В. М. Монахова, определяет методологию проектирования «системы с заданными свойствами» [4, с. 59], которая соответствует концептуальным основам трансдисциплинарности. Мы выделили мотивационно-целевой, содержательно-процессуальный и трансдисциплинарных образовательных маршрутов. На мотивационно-целевом уровне актуализируется цель технологии проектирования индивидуальных образовательных маршрутов, которая заключается в активизации осознанности собственной деятельности, в стимулировании автономности личности студентов в ситуации имитационного моделирования. В этой связи организация практико-ориентированной подготовки предполагает «продвижение» студента от репродуктивной деятельности к продуктивной, от индивидуализма к продуктивной совместной деятельности, a проектирование индивидуальных образовательных маршрутов в соответствии с концепцией проектирования Е.В. Везетиу является «одним из основных компонентов профессиональной деятельности педагога, включающим педагогические действия, основанные на осознании цели деятельности, способов, приемов, методов и форм ее достижения [1, с. 37].

Второй блок технологии реализации индивидуальных образовательных маршрутов органично связан с реализацией концепции политомических «переходов» в процессе практико-ориентированной подготовки. Для решения комплексной проблемы политомических «переходов» в качестве методов обучения, обеспечивающих качественные изменения результатов в рамках когнитивного опыта решения задач практикоориентированной подготовки, мы использовали методы трансдисциплинарных кейсов, многомерных матриц и метод межпредметного погружения. Методы обучения в условиях политомических «переходов» должны обеспечивать не только когнитивный перенос способов действий, но и обогащать субъектный опыт студентов.

Третий блок технологии предоставляет собой описание диагностического инструментария оценки эффективности освоения будущими педагогами физической культуры индивидуальных образовательных маршрутов. В качестве уровней освоения индивидуальных образовательных маршрутов нами выделены рефлексивно-гностический, интерактивноконструктивный и перцептивно-проективный. Отметим, что в соответствии с концепцией политомических «переходов», описание уровней представляет собой качественные показатели, а не описание результата в дихотомии «от большего к меньшему». 
Так, рефлексивно-гностический уровень освоения индивидуально-образовательных маршрутов предполагает формирование системной рефлексии как уникальной способности субъекта обучения посмотреть на себя со стороны. Интерактивно-конструктивный уровень освоения индивидуальных образовательных маршрутов представляет собой «проживание» студентами ситуаций имитационного моделирования. Для будущих педагогов такая ситуация обогащается формированием интериоризированной и экстериоризированной телесности как системы представления о собственном теле и способах «воздействия» на телесность Другого. Перцептивно-проективный уровень освоения индивидуальных образовательных маршрутов предполагает качественное изменение восприятия учебного процесса, изменение мотивационно-целевых установок, связанных с будущей педагогической деятельностью.

Проектирование трансдисциплинарных индивидуальных образовательных маршрутов практико-ориентированной подготовки бакалавров осуществлялось на базе научноисследовательской лаборатории кафедры теории и методики физической культуры и спорта Высшей школы физической культуры и спорта ЮУрГГПУ «Трансдисциплинарная лаборатория образовательных ресурсов в сфере физической культуры и спорта». Конструктор индивидуальных образовательных маршрутов бакалавров состоит из двух основных частей: информационной и статистической. Информационная часть включает разделы: «Информационно-методическое сопровождение деятельности лаборатории», «Учусь учить», «Трансдисциплинарные практикумы и мастер-классы», «Онлайн курсы для студентов», «Трансдисциплинарное проектирование самостоятельной работы студентов». Статистическая часть включает формы для заполнения студентами и преподавателями и страницы интерпретации результатов. Проектирование индивидуальных образовательных маршрутов на базе «Трансдисциплинарной лаборатории образовательных ресурсов в сфере физической культуры и спорта» создает возможность учета мнений, эффективного взаимодействия и совместной работы бакалавров в сфере физической культуры и преподавателей. Статистическая часть содержит банк методик, позволяющих интерпретировать полученные результаты, представить их наглядно, а также сделать вывод об эффективности реализации ИОМ и своевременно его корректировать. В дальнейшем в рамках «Трансдисциплинарной лаборатории образовательных ресурсов в сфере физической культуры и спорта» возможно отражение следующих уровней реализации ИОМ:

1. для обучающихся, осваивающих образовательные программы учебных предметов на базовом уровне;

2. для обучающихся, осваивающих образовательные программы учебных предметов на углубленном уровне;

3. для подготовки научно-исследовательских работ и подготовки к предметным олимпиадам.

Трансдисциплинарные индивидуальные маршруты отражают новое видение практикоориентированной подготовки, создавая перспективы поливариантности методов и форм обучения, проектируя политомические переходы результатов обучения будущих педагогов физической культуры ситуации имитационного моделирования. Более того, такой подход к проектированию индивидуального маршрута предполагает не только «мониторинг результатов» [4, с. 60], но и организацию системы психолого-педагогического сопровождения реализации потенциальных возможностей студентов. и сопровождение ученика по маршруту с целью оптимизации и процесса, и результатов, так как трансдисцилинарность «вносит» в образовательный процесс особый потенциал, которой «работает» на будущего педагога физической культуры многовариантно и многоаспектно. Однако при всем этом маршрут остается в рамках образовательной программы, направляется и регулируется ею. 
Образовательная программа остается основным ориентиром и регулятором механизмов формирования индивидуального образовательного маршрута, на которую накладываются индивидуальные особенности ученика.

Таким образом, практико-ориентированная подготовка бакалавров предполагает решение проблем, связанных с совершенствованием потребностно-мотивационной сферы студентов, включающей особенности формирования мотивов учебной деятельности, а также высокого уровня познавательной активности, обусловливающей целенаправленную деятельность в рамках синтеза нового знания в процессе реализации политомических «переходов».

\section{Литература}

1. Везетиу Е.В. Проектирование, педагогическое проектирование, проектирование образовательного процесса: обоснование сущности понятий // Проблемы современного педагогического образования. 2019. № 65-1. С. 53-55.

2. Жабаков В.Е., Жабакова Т.В., Кравцова Л.М. Трансдисциплинарный подход к подготовке будущих педагогов физической культуры. Челябинск: Южно-Уральский научный центр РАО, 2020. 243 с.

3. Лубский А.В. Трансдисциплинарные исследования: проблемы современного эпистемологического дискурса // Гуманитарные, социально-экономические и общественные науки. 2016. С. 61-66.

4. Монахов В.М. Технология проектирования методических систем с заданными свойствами // Высшее образование в России. 2011. № 6. С. 55-59.

5. Павлова Л.В. Практико-ориентированное обучение (из опыта стажировки в Швейцарии) // Социосфера. 2013. № 4. С. 91-92.

(C) Жабаков В.Е., Макаренко В.Г., 2021 